\title{
Clinical applications of corneal confocal microscopy
}

\author{
Mitra Tavakoli' \\ Parwez Hossain ${ }^{2}$ \\ Rayaz A Malik' \\ 'Division of Cardiovascular \\ Medicine, University of Manchester \\ and Manchester Royal Infirmary, \\ Manchester, UK; ${ }^{2}$ University of \\ Southampton, Southampton Eye \\ Unit, Southampton General Hospital, \\ Southampton, UK
}

\begin{abstract}
Corneal confocal microscopy is a novel clinical technique for the study of corneal cellular structure. It provides images which are comparable to in-vitro histochemical techniques delineating corneal epithelium, Bowman's layer, stroma, Descemet's membrane and the corneal endothelium. Because, corneal confocal microscopy is a non invasive technique for in vivo imaging of the living cornea it has huge clinical potential to investigate numerous corneal diseases. Thus far it has been used in the detection and management of pathologic and infectious conditions, corneal dystrophies and ecstasies, monitoring contact lens induced corneal changes and for pre and post surgical evaluation (PRK, LASIK and LASEK, flap evaluations and Radial Keratotomy), and penetrating keratoplasty. Most recently it has been used as a surrogate for peripheral nerve damage in a variety of peripheral neuropathies and may have potential in acting as a surrogate marker for endothelial abnormalities.
\end{abstract}

Keywords: corneal confocal microscopy, cornea, infective keratitis, corneal dystrophy, neuropathy

\section{Introduction}

Ocular diagnostic imaging techniques have evolved rapidly over the last ten years. The clinical diagnostic capability of detecting both anterior and posterior segment diseases has grown exponentially in accord with technological innovation. Corneal confocal microscopy is a relatively new technique which until recently has been used predominantly in clinical research. However, it has emerged as a powerful technique for the study of corneal cellular structure. The present review will summarize current knowledge of this technique, the basis on which images are interpreted and analyzed and its huge potential for clinical application.

\section{Optical principles}

Minsky (1988) developed the original confocal microscope in 1955 to image brain cells and study neural networks in the living brain. Subsequently, the optical theory of confocal microscopy was more formally developed and extended during the 1980s (Wilson and Sheppard 1984) and 1990s (Hill 1994; Masters and Thaer 1994).

In short, the basic principle of a confocal microscope is that a single point of tissue can be illuminated by a point light source and simultaneously imaged by a camera in the same plane, ie, it is "confocal" (Figure 1). This produces an image with a very high resolution but it has virtually no field of view due to a single point of illumination and detection. To solve this problem, the instrument instantaneously illuminates and synchronously images, ie,scans, a small region of tissue with thousands of tiny spots of light which are reconstructed to create a usable field of view with high resolution and magnification (Efron et al 2001).

The result is that confocal microscopes provide an en face, view of the structure being analyzed. Because the cornea is transparent, white light or more recently lasers 


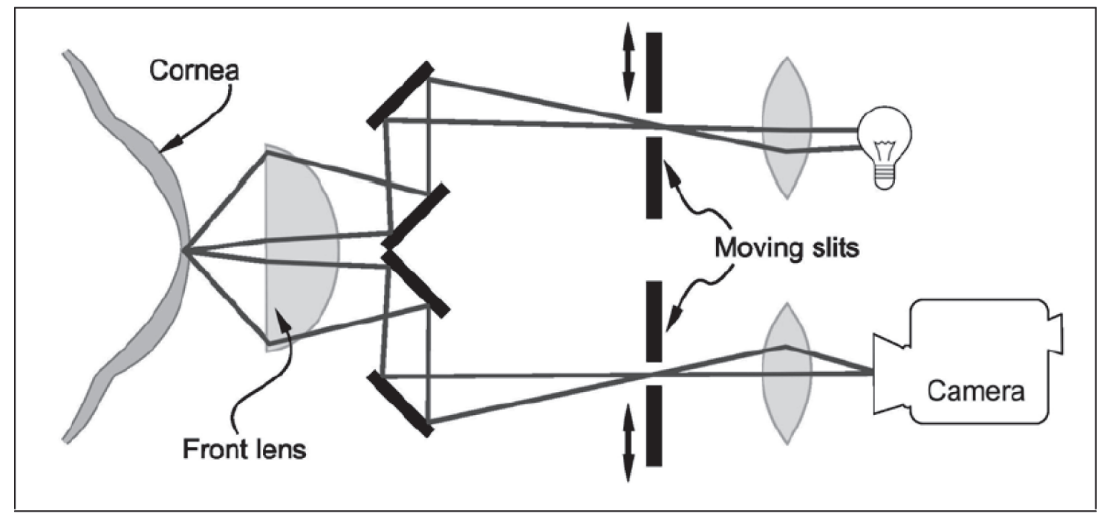

Figure I Optical principle of the confocal microscope. (Courtesy of Nidek Technologies, from Mastropasqua and Nubile 2002).

can be used to image it in vivo at high magnification (cellular level) and a high resolution, providing a depth of field $\sim 10 \mu \mathrm{m}$, lateral resolution $\sim 1 \mu \mathrm{m}$ and a field of view $\sim 300 \mu \mathrm{m} \times 220 \mu \mathrm{m}$ (Tomey Confoscan).

\section{Current corneal confocal imaging systems}

At present there are several confocal imaging microscopes which are commercially available and include: Confoscan P4 (Tomey Corporation, Cambridge, MA, USA), Confoscan 4 (Nidek Technologies, Japan) and the most recent clinical device which is a laser corneal confocal microscope (Heidelberg Retina Tomograph II Rostock Corneal Module (HRTII)) (Heidelberg, Germany).

The primary advantage of laser scanning confocal microscopy is the ability to serially produce images of thin layers from the cornea. According to this the depth of focus for the TSCM (Tandem scanning confocal microscope) is $7-9 \mu \mathrm{m}$, and in slit scanning systems it is $26 \mu \mathrm{m}$ whilst it is $5-7 \mu \mathrm{m}$ using the laser confocal microscope.

When examining the conjunctiva and corneoscleral limbus the major limitation of the white light in-vivo confocal microscope is due to the back-scattering of light. However, laser scanning technology combined with the Rostock Cornea Module (RCM) microscope appears to be less affected by back-scatter enabling accurate imaging of the cornea and conjunctiva. The conjunctiva, peripheral cornea and limbus are therefore best examined at the surface and at medium depth using the HRT II Cornea than with a standard confocal microscope.

\section{Confocal images of corneal layers}

Confocal microscopy provides images which are comparable to in-vitro histochemical techniques of each of the five basic layers: corneal epithelium, Bowman's layer, stroma, Descemet's membrane and corneal endothelium (Figure 2).

\section{Corneal epithelium}

In greater detail the corneal epithelium consists of three layers - the superficial cells, wing cells and basal cells (Figure 3).

\section{Superficial cells}

Superficial cells are polygonal, $40-50 \mu \mathrm{m}$ in diameter and approximately $5 \mu \mathrm{m}$ thick (Masters and Thaer 1995; Tomii et al 1994). They exhibit small bright rounded nuclei, surrounded by a darker cytoplasm with a perinuclear hypo reflective dark ring and a well defined cell border. Superficial cells often display a large variation in cytoplasmic reflectivity, which is thought to represent various stages of progression towards cell death, with the darker cells being those about to desquamate (Wilson and Hong 2000). Large dark featureless areas are evident between cells.

\section{Wing cells}

Wing cells are located in the intermediate level of the epithelial cells with a variable size and shape and are typically $30-45 \mu \mathrm{m}$. They are characterized by bright cell borders and a bright cell nucleus with few organelles and the nucleous is not usually visible (Masters and Thaer1995).

\section{Basal cells}

Basal cells are $10-15 \mu \mathrm{m}$ in diameter and their cell nuclei are not visible. They display a uniformly bright cell border with a dark cytoplasmic mass (Tomii et al 1994; Harrison et al 2003).

Confocal microscopy has demonstrated a reduction in basal cell density in diabetic patients compared to control 


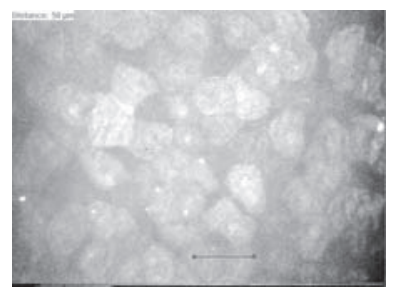

(a)

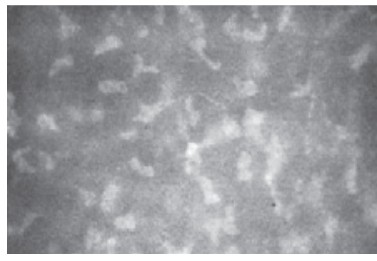

(d)

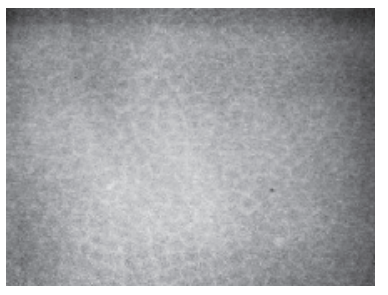

(b)

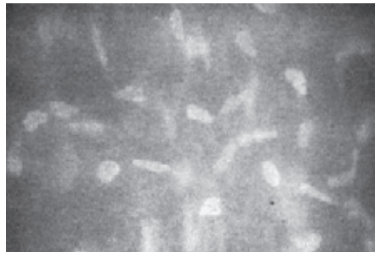

(e)

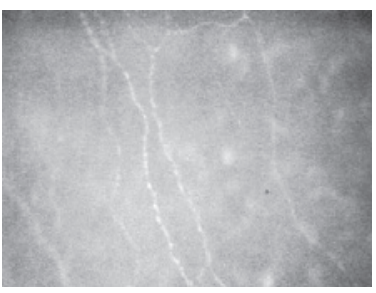

(c)

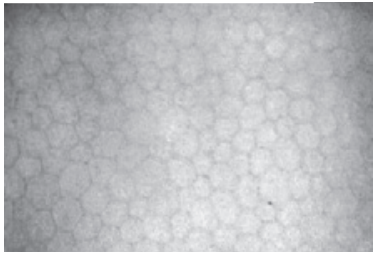

(f)

Figure 2 Confocal microscopic corneal images (a) superficial epithelium (b) Basal membrane (c) Bowman's layer (d) anterior stroma (e) posterior stroma (f) Endothelium. (The instrument used for all the pictures in this paper was the Tomey Confoscan P4 in-vivo slit-scanning real-time confocal microscope (Erlangen, Germany)).

subjects (Chang et al 2006; Quadrado et al 2006). It has also shown an increase in the light-scattering index (a quantitative measure of tissue reflectivity) in diabetic patients, reflecting an increasing abnormality in the basement membrane of patients with diabetes (Morishige et al 2001).

\section{Bowman's membrane (anterior limiting lamina)}

Bowman's layer is an amorphous membrane located immediately posterior to the basal epithelium which is approximately $10 \mu \mathrm{m}$ thick and is made of collagen fibers and contains unmyelinated c-nerve fibers (Patel et al 1998; Wilson and Hong 2000; Kobayashi et al 2006). Confocal microscopic images of the Bowman's membrane are featureless and grey (Figure 4), with discrete beaded nerve bundles of the sub-basal nerve plexus traversing the field of view. Although single nerve fibers often run in the same nerve bundle, the limited resolution of confocal microscopy permits the visualization of the more reflective beaded nerve fibers only (Auran et al 1995; Müller et al 1996, 1997; Oliveira-Soto and Efron 2001). Some keratocytes in the anterior stroma may be seen in the background.

Confocal microscopy has been used to show that increasing age results in a decrease in nerve fiber density, but there is no effect on the nerve fiber diameter or beading frequency (Grupcheva et al 2002). Several authors have demonstrated a significant alteration in corneal nerve fiber morphology in Bowman's layer of diabetic patients which have been related to the severity of somatic neuropathy (Rosenberg et al 2000; Malik et al 2003; Kallinikos et al 2004; Hossain et al 2005; Chang et al 2006). This will be discussed in more detail later. (a)

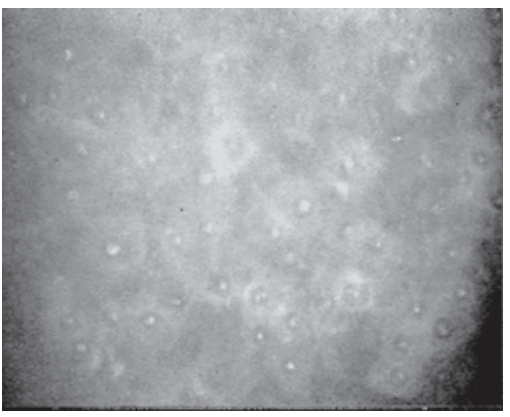

(b)

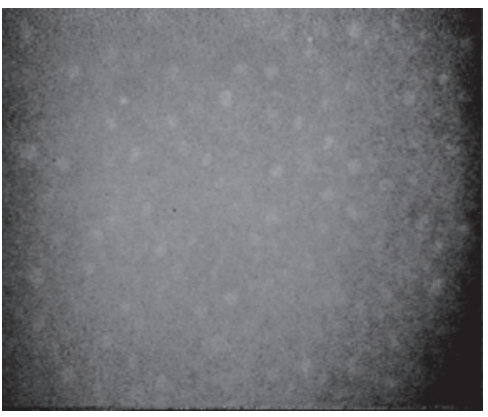

(c)

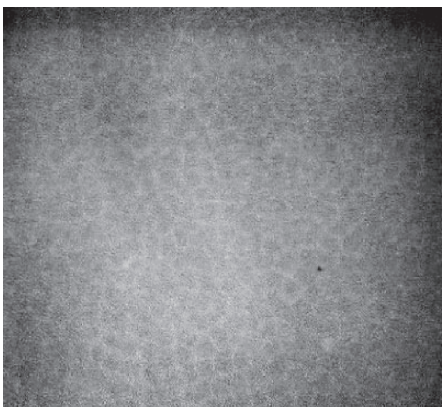

Figure 3 Confocal microscopic images of epithelial layer of cornea: (a) the superficial epithelial cells, (b) wing cells, (c) basal cells. 
(a)

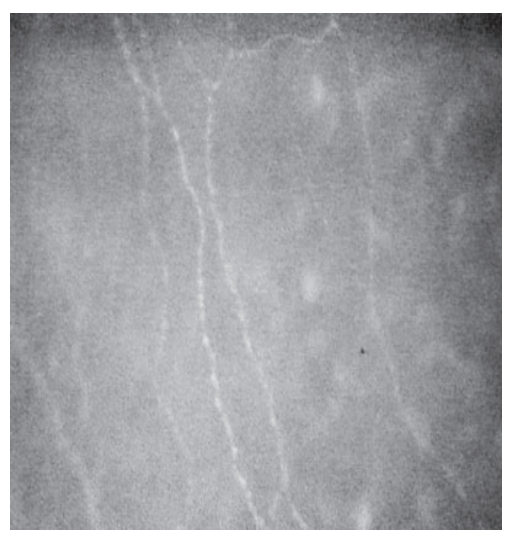

(b)

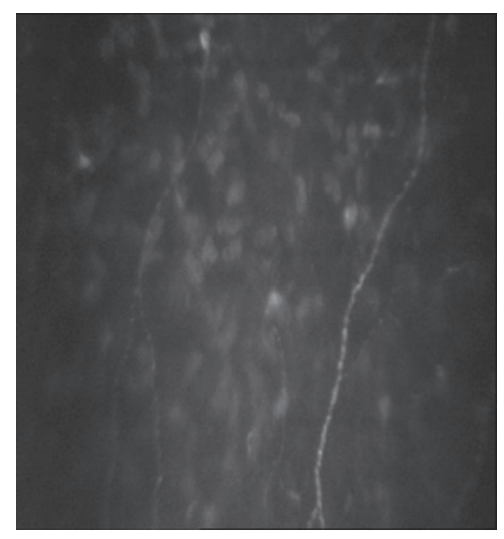

(c)

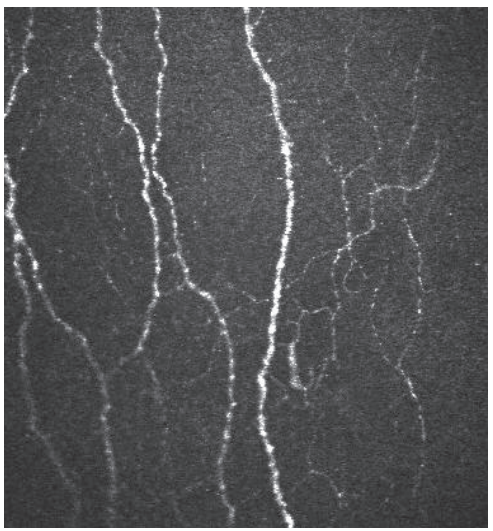

Figure 4 Confocal microscopic images of Bowman's membrane with nerve fibres. (a) Tomey confoscan P4, (b) Nidek confoscan 4, (c) laser HRT II.

\section{Corneal stroma}

The stroma accounts for $90 \%$ of the thickness of the cornea and is composed of collagen fibers, interstitial substance and keratocytes. The collagen fibers and interstitial substance are transparent and essentially form the grey amorphous background of the confocal microscopic images. Keratocyte nuclei are 5-30 $\mu \mathrm{m}$ in diameter; have a varied shape being bean-like in the anterior stroma, and oval shaped in the posterior stroma. They can be identified as discrete bright entities against a grey background (Figures $5 \mathrm{a}$ and $5 \mathrm{~b}$ ). The cytoplasm, cell walls and processes cannot be visualized (Hahnel et al 2000). Myelinated A $\delta$ fibers with a diameter ranging from 4 to $8 \mu \mathrm{m}$ can also be seen in the anterior stroma (Müller et al 2003) but unlike nerves in Bowman's layer, their orientation and size is highly variable which makes quantification difficult (Figure 5c).

A recent study has shown no significant difference in the number of stromal cells between diabetic patients and control subjects (Quadrado et al 2006). However, stromal nerve thickness has been shown to be significantly increased in diabetic patients compared to control subjects (Mocan et al 2006).

\section{Descemet's membrane (posterior limiting lamina)}

Descemet's membrane is the basement membrane of the corneal endothelium and confocal images of this structure are acquired in the course of through-focusing from the posterior stroma to the endothelial cells. Images of Descemet's membrane have a generalized hazy appearance and no cellular structures can be identified (Figure 6). The normal Descemet's membrane is not visible in young subjects but becomes more visible with increasing age (Hollingsworth et al 2001).

\section{Corneal endothelium}

This layer is comprised of a single layer of endothelial cells which are 4-6 $\mu \mathrm{m}$ thick and $20 \mu \mathrm{m}$ in diameter with a hexagonal or polygonal shape and are easily identified with confocal microscopy as bright cell bodies with dark cell borders (Figure 7). The cell nuclei are rarely recognizable, and the (a)

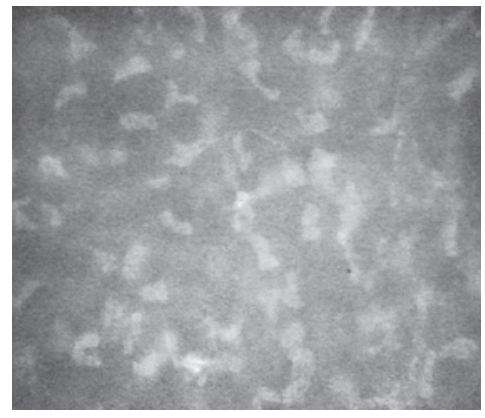

(b)

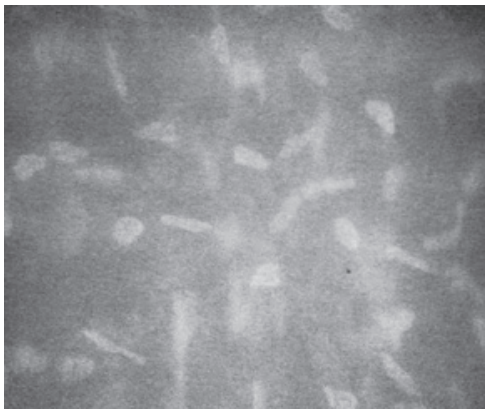

(c)

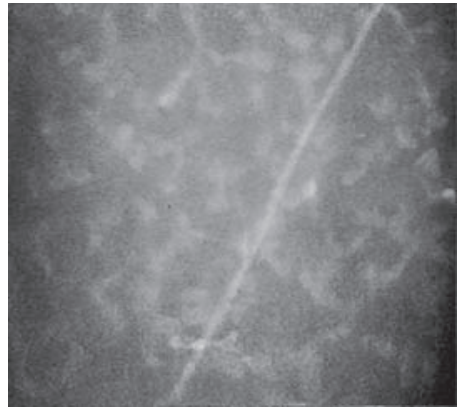

Figure 5 Confocal microscopic images of the stroma (a) anterior (b) posterior (c) stromal nerves. 


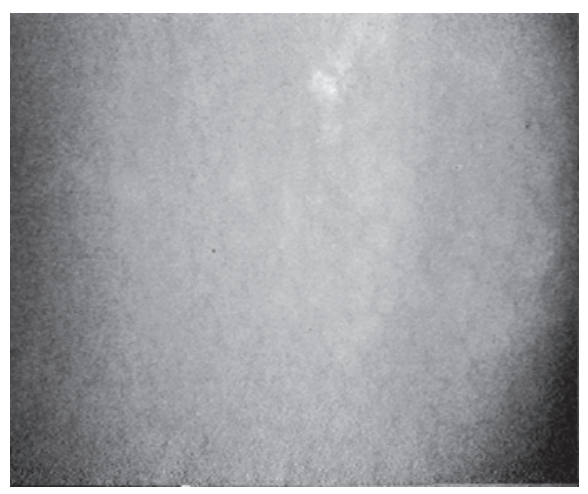

Figure 6 Confocal microscopic images of the Descemet's membrane.

cellular body is homogeneously bright with clearly defined borders.

Increasing age causes a reduction in endothelial cell density by approximately $0.6 \%$ a year (Efron et al 2001; Joyce 2003 ) and an increase in polymegathism (variation in cell size) (Efron et al 2001). Diabetic patients show an increase in endothelial damage (Inoue et al 2002) and polymegathism with increasing duration of diabetes (Lee et al 2006). There may also be a differential loss of endothelial cells with one study demonstrating a reduction in mean cell density of 5\% in type 2 and $11 \%$ in type 1 diabetes compared to an agematched control group (Roszkowska et al 1999).

\section{Measuring corneal thickness with corneal confocal microscopy}

One of the most important advances in confocal imaging has been the development of confocal microscopy 'through focusing' (CMTF) (also known as Z-Scan mode) which enables the measurement of corneal thickness. As all points of the CTMF curve correlate directly with high resolution images, the exact position in the Z-axis of determinate structures such as the epithelial surface, the sub epithelial

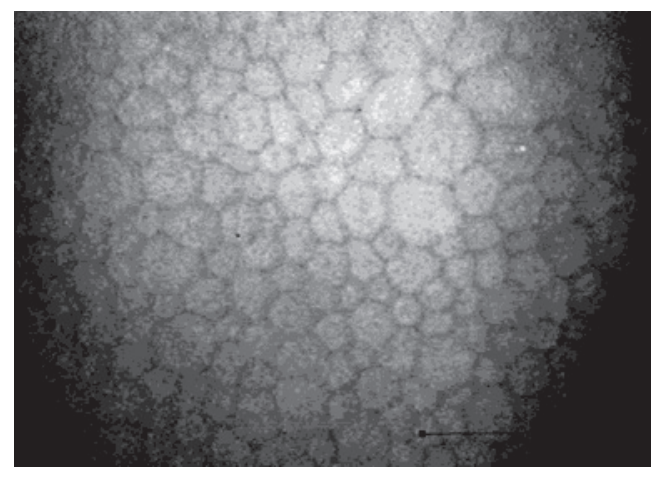

Figure 7 Confocal microscopic image of the endothelium. nerve plexus, and the endothelium can be used to precisely calculate the distance between the different corneal layers (Figure 8). In a Z-Scan profile curve the percentage reflected light intensity (y-axis) is plotted against the distance in the cornea in $\mu \mathrm{m}$ (x-axis).

This method has been used in several studies and has shown high reliability (McLaren et al 2004; Javaloy et al 2004; Brugin et al 2007). The most accurate way of measuring was reported by Brugin et al (2007) who used a corneal confocal microscope with z-ring adapter. Thus the corneal confocal microscope may also provide a means to undertake diagnostic pachymetry enabling accurate, reproducible assessment of corneal thickness.

\section{Clinical applications of confocal microscopy}

Because, corneal confocal microscopy is a non invasive technique for in vivo imaging of the living cornea it has been used to investigate numerous corneal diseases. It can provide a qualitative morphological description or it can be used to quantify pathology such as corneal nerve and endothelial cell shape and density or three dimensional kinetic images of the living human cornea (Bohnke et al 1999). Thus it can be used in the detection and management of pathologic and infectious conditions, detection and management of corneal dystrophies and ecstasies, monitoring contact lens induced corneal changes, for pre and post surgical evaluation (PRK, LASIK and LASEK, flap evaluations and Radial Keratotomy), and to monitor penetrating keratoplasty. Most recently it has been used as a surrogate for peripheral nerve damage in a variety of peripheral neuropathies. The ability to distinguish between corneal edema due to corneal graft rejection (caused by presence of inflammatory cells) and endothelial decomposition (caused by low endothelial cell counts without the presence of inflammatory cells) is one of the other advantages of CCM. Cell densities in different layers from the epithelium to the endothelium, including immune cell densities, can be monitored using corneal confocal microscopy.

Confocal microscopy has been shown to be useful in the early detection and diagnosis of several conditions and also as a means to observe and monitor the effects of disease and therapeutic intervention (Bohnke and Masters 1999; Rosenberg et al 2000; Oliveria-Soto et al 2001; Hollingsworth et al 2001; Jalbert et al 2003; Tervo and Moilanen 2003, 2002; Kallinikos et al 2004). A brief summary of published studies utilising CCM to define the 


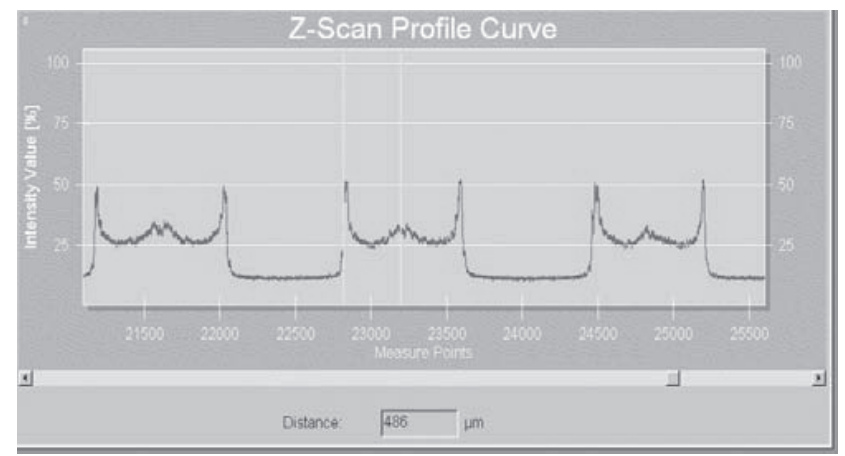

Figure 8 Measurement of corneal thickness using the Z-Scan mode of the TOMEY Confoscan P4.

pathology in various diseases and to examine the effects of refractive surgery and contact lens wear are listed in Table 1.

\section{Infective keratitis}

Identification of the causative organism in patients with infective keratitis is of considerable clinical importance and several studies have revealed the usefulness of confocal microscopy in diagnosing Acanthamoeba keratitis (Chew 1992; Auran et al 1994; Winchester et al 1995; Cavanagh and McCulley 1996; Pfister et al 1996; Mathers et al 1996, 1997; Kaufman et al 2004 ), Aspergillus keratitis (Winchester et al 1997), microsporidial keratitis (Shah et al 1996), fungal keratitis (Florakis et al 1997; Winchester et al 1997), Herpes keratitis (Cavanagh et al 1993; Rosenberg et al 2002), contact lens related bacterial keratitis (Kaufman et al 1996), crystalline keratitis (Sutphin et al 1997) and mixed bacterial keratitis (Su et al 2006).

\section{Corneal dystrophies}

Until recently, the clinical evaluation, diagnosis, and differentiation of corneal dystrophies was based on slit-lamp biomicroscopy. However, this technique cannot provide information at the cellular level and the only means of providing this was by biopsy with histopatological examination, which is clearly an invasive procedure. Because confocal microscopy can visualize alterations non-invasively at a cellular level it has been applied to diagnose Fuchs' endothelial dystrophy (Kaufman et al 1993; Mustonen et al 1998; Chiou et al 1999a; Hollingsworth et al 2000), posterior polymorphous dystrophy (Chiou et al 1999b; Chiou, Beuerman et al 1999) and the iridocorneal endothelial syndrome (Cavanagh et al 1993; Chiou et al 1999c) and has also been used to distinguish between different types of dystrophy in Bowman's layer (Kobayashi et al 2007) and the stroma (Werner 1999).

Different studies using CCM demonstrate significant qualitative and quantitative alterations in all corneal layers in the eyes of patients with keratoconus. A study comparing in-vitro light microscopy and in vivo CCM (Hollingsworth et al 2005) showed that CCM provides the same level of structural detail as light microscopy (Brookes et al 2003). A significant enlargement in the epithelial cells was observed compared to control subjects and in the superficial layer, the cells appeared to be arranged in a whorl-like fashion

Table I A summary of quantitative in vivo confocal microscopy studies of the cornea, layer by layer in disease, refractive surgery and contact lens-induced changes

\begin{tabular}{ll}
\hline Investigator & Abnormality \\
\hline Epithelium & \\
Mustonen 1998 & Fuchs' endothelial dystrophy \\
Morishige 200I; Quadrado 2006; Chang 2006 & Diabetes \\
Bowman's layer & \\
Rosenberg 2000; Malik 2003; Kallinikos 2004; Hossain 2006; Chang 2006 & Diabetic neuropathy \\
Benitez-Del-Castillo 2007,2004; Hosal 2005;Tuominen 2003 & Dry Eye, Sjogren's syndrome \\
Brooks 2003; Patel 2006; Simo Mannion 2005 & Keratoconus \\
Heinz 1996; Kauffmann 1996; Moilanen 2003; Bragheeth 2005 & Corneal nerve regeneration after refractive surgery \\
Stroma and Keratocyte & \\
Erie 2002; Hollingsworth 2005; Patel 2002 & Keratocyte density in keratoconus \\
Jalbert 1999; Kallinikos 2004, 2006 & Effect of lens wear on corneal stroma and \\
Quadrado 2006; Mocan 2006 & keratocyte density \\
Erie 2003 & Diabetes \\
Perez-Gomez 2003; Mitooka 2002; Pisella 200I & Keratocyte density after PRK \\
Endothelium & Keratocyte density after LASIK \\
Patel 2002 & \\
Hara 2003; Mustonen 1998 & Contact lens wearers \\
O’Donnell 2004 & Fuchs corneal endothelial dystrophy \\
\hline
\end{tabular}


(Somodi et al 1996; Hollingsworth et al 2005). CCM has revealed a significant reduction in nerve density in the keratoconic cornea. (Simo Mannion et al 2005; Patel et al 2006) and most recently, a study using laser corneal confocal microscopy showed an abnormal sub-basal nerve architecture in patients with keratoconus compared to normal corneas. (Patel et al 2006). The reflectivity of cells in the stromal layer is also increased (Somodi et al 1996; Hollingsworth et al 2005), but the number of keratocyte cells is decreased significantly in these patients, with no significant difference in endothelial polymegathism (Hollingsworth et al 2005).

\section{Refractive surgery and corneal wound healing}

An assessment of wound healing following surgical intervention or injury is of considerable clinical importance. Confocal microscopy thus seems to be a good tool for studying, in vivo, corneal evolution after surgery, because it is able to show cellular modifications inside the corneal layers (Cavanagh et al 1993; Kaufman et al 2006).

Following photorefractive keratectomy (PRK) temporal changes in keratocyte density, subepithelial deposits, stromal changes and nerve regeneration have been qualitatively and quantitatively assessed (Corbett et al 1996; Heinz et al 1996; Linna and Tervo 1997; Kauffmann et al 1996; Böhnke et al 1998; Moilanen 2003). Corneal nerve degeneration and repair have also been investigated following injury (Auran et al 1995; Petroll et al 1996), and penetrating keratoplasty (Cohen et al 1995; Richter et al 1996).

As Laser in situ keratomileusis (LASIK) has become the most popular procedure in ophthalmology, confocal microscopy has been used in several studies to investigate post LASIK corneal wound healing. Thus it has been shown that the density of keratocytes decreases after PRK and LASIK for up to 5 years (Erie, McLaren et al 2005a; Erie et al 2006). Regeneration of the corneal sub basal nerves after LASIK has been studied quantitatively and qualitatively using the confocal microscope. (Linna et al 2000; Erie et al 2002a; Mitooka et al 2002; Avunduk et al 2004). Calvillo et al (2004) reported that the number and density of subbasal nerves decreased by $90 \%$ in the first month after LASIK and that these nerves began to recover by 6 months and recovered completely by 2 years. At the same time, the mean orientation of the subbasal nerves did not change from the predominantly vertical orientation observed before LASIK. Lee et al (2002) found that the number of subbasal nerve fibers imaged decreased by more than $90 \%$ one week after LASIK and increased between 6 and 12 months after surgery but remained at less than half of the preoperative value. Erie et al (2005b) found that the subbasal nerve density recovered to the preoperative nerve density five years after LASIK.

Lee et al (2006) recently reported on subbasal nerve regeneration after LASEK and showed that the subbasal nerve density decreased significantly after LASEK and did not return to preoperative levels up to 6 months postoperatively.

Therefore, the confocal microscope is a unique diagnostic instrument that can be used to evaluate corneal healing, long-term stability and to assess complications after refractive surgery. The ability of the device to view in-vivo cellular detail, micro organisms, inflammatory cells, epithelial cells, fibrosis and measure the thickness of the cornea after laser in-situ keratomileusis, in a non invasive manner, highlights the unique capabilities of this instrument.

\section{Contact lens-induced corneal changes}

Confocal microscopy has been used to study contact lensinduced corneal changes by several authors (Efron et al 2002; Patel 2002; Kallinikos et al 2004; O'Donnell et al 2004, 2001; Olivera-Soto et al 2003; Hollingworth et al 2004).

Confocal microscopy has led to the identification of a new type of chronic stromal change in patients who wear contact lenses (Kaufman et al 1996; Böhnke et al 1997; Jalbert et al 1999). Extended contact lens wear causes a loss of keratocytes (Efron et al 2002). The underlying basis for this has been elucidated recently showing that the physical presence of a contact lens induces the release of inflammatory mediators that may cause keratocyte dysgenesis or apoptosis (Kallinikos et al 2004). A reduction in corneal sensitivity occurs in patients with long term contact lens wear (Patel et al 2002), however neither short-term (overnight wear) (Efron et al 2002) nor long-term (12 months extended wear) (Efron et al 2002) soft contact lens wear appears to affect the morphology and/or distribution of corneal nerves viewed using confocal microscopy (Olivera-Soto et al 2003). In a study using corneal confocal microscopy in diabetic patients, the morphology of endothelial cells in diabetic patients who wore soft contact lenses was not appreciably different from non-diabetic control subjects wearing contact lenses (O’Donnell et al 2004).

\section{Corneal microdeposits}

Corneal confocal microscopy has been used to identify corneal microdeposits associated with a variety of pathological conditions including: Fabry's disease (Font et al 1972), Wilson's disease (Wiebers et al 1977), hyperlipidemia 
(Pe'er et al 1983), and long-term contact lens wear (Bohnke et al 1997). It has also been used to identify the side effects of Amiodarone (Mantyjarvi et al 1998; Mastropasqua et al 2002) and the development of microdeposits following refractive surgery (Figure 9) (Bohnke et al 1998).

\section{Corneal nerve morphology}

The cornea is the most densely innervated part of the human body containing myelinated $\mathrm{A} \delta$ and unmyelinated $\mathrm{C}$ fibers derived from the ophthalmic division of the trigeminal nerve. Normal corneal nerve morphology has been studied in healthy subjects by light and electron microscopy (Muller et al 1996, 1997 ) and more recently confocal microscopy (OliveiraSoto et al 2001; Grupcheva et al 2002). Several groups have employed corneal confocal microscopy to demonstrate that corneal small nerve fiber damage is directly related to the severity of somatic neuropathy (Figure 10) (Rosenberg et al 2001; Malik et al 2003; Kallinikos et al 2004).

We have also shown that corneal nerve fiber density improves with improved glycemic control over 24 months (Iqbal et al 2005) and within 6 months of pancreas transplantation in patients with Type 1 diabetes (Mehra et al 2006).
Therefore we have proposed that corneal confocal microscopy, might be an ideal surrogate endpoint for evaluating therapeutic efficacy in clinical trials of human diabetic neuropathy (Hossain et al 2005). Additionally we have used this technique to quantify corneal nerve abnormalities in a range of other peripheral neuropathies including Fabry's disease and idiopathic small fiber neuropathy (Tavakoli et al 2006).

\section{Future developments}

Confocal microscopy is a powerful diagnostic technique which allows non-invasive microscopic examination of the cornea. However, until recently its use in clinical practice has been limited to research centers. One of the major limitations has been the acquisition of high quality and reproducible images with a systematic approach to quantification of structural alterations. This has been overcome in recent years, in part due to the huge improvement in digital systems enabling data compression and facilitating data storage. The quality of acquired images has improved dramatically and new options for data analysis and data interpretation have become available with newer instruments which are smaller and less expensive. With regard to quantifying morphology, (a)

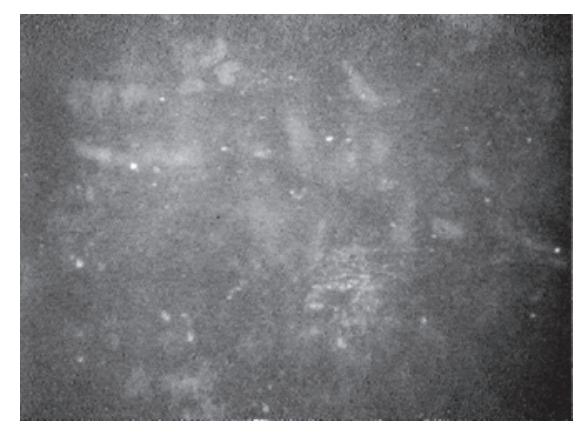

(b)

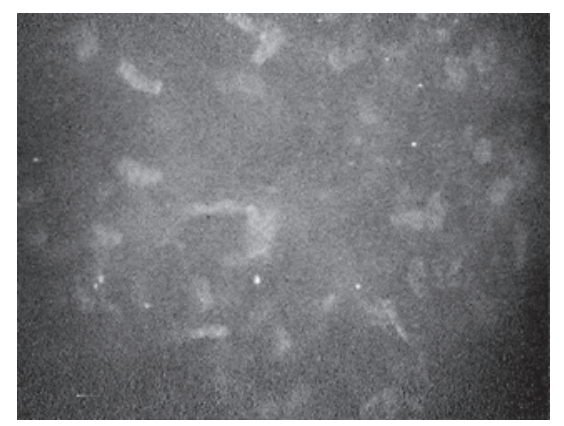

Figure 9 Microdeposits in the stromal layer of a patient after PRK (a) after I week (b) after 6 months.

(a)

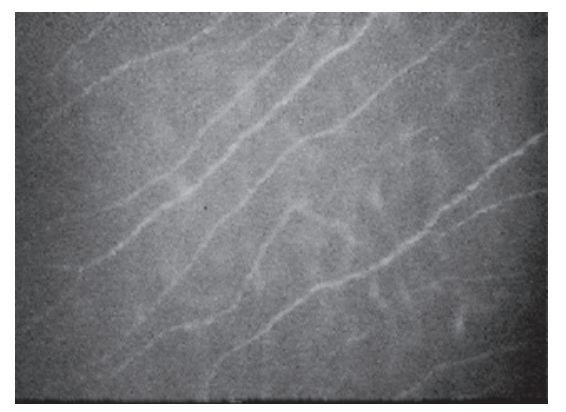

(b)

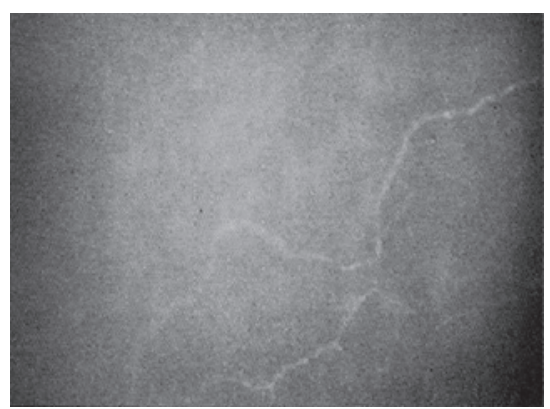

Figure 10 Image of corneal nerves in Bowman's layer from (a) healthy subject (b) diabetic patient. 
computer-assisted image analysis with defined algorithms may improve the accuracy and repeatability of morphometric parameters defining corneal morphology and real-time 3-dimensional reconstruction will provide a better means of quantifying tissue and cellular architecture (Stachs et al 2006). Furthermore, developing techniques which map the whole cornea will undoubtedly provide more robust and complete quantification (Patel et al 2005, 2006). With regard to corneal nerves in patients with peripheral neuropathy, the construction of 3-D nerve maps would significantly enhance the assessment of branching and hence repair, over time and in response to therapeutic intervention. Additional aspects which merit further assessment include study of the Langerhans cells which may provide insights into basic pathogenic mechanisms of corneal damage and also the immune response to tissue injury (Rosenberg et al 2002; $\mathrm{Su}$ et al 2006; Zhivov et al 2005, 2007).

\section{Conclusion}

Confocal microscopy allows non-invasive in vivo imaging of all layers of the cornea enabling the clinical investigation of numerous corneal diseases. In this brief review we have evaluated the considerable potential of this powerful technique to undertake detailed morphological analysis of corneal structures. In clinical ophthalmology, facilitating the diagnosis of infectious keratitis and assessing tissue repair following surgical intervention or injury holds considerable promise. However, its widest application may well come in the field of metabolic or neurological disease, as it may provide a means to identify patients at risk, follow progression and measure therapeutic response in not only diabetic neuropathy but also a range of other neuropathies.

\section{References}

Auran JD, Koester CJ, Kleiman NJ, et al. 1995. Scanning slit confocal microscopic observation of cell morphology and movement within the normal human anterior cornea. Ophthalmology, 102:33-41.

Auran JD, Starr MB, Koester CJ, et al. 1994. In vivo scanning slit confocal microscopy of Acanthamoeba keratitis. A case report. Cornea, 13:183-5.

Avunduk AM, Senft CJ, Emerah S, et al. 2004. Corneal healing after uncomplicated LASIK and its relationship to refractive changes: A six-month prospective confocal study. IOVS, 45:1334-9.

Benitez-Del-Castillo JM, Acosta MC, Wassfi MA, et al. 2007. Relation between corneal innervation with confocal microscopy and corneal sensitivity with noncontact esthesiometry in patients with dry eye. Invest Ophthalmol Vis Sci, 48:173-81.

Beuerman RW, Laird JA, Kaufman SC, et al. 1994. Quantification of real-time confocal images of the human cornea. J Neurosci Methods, 54:197-203

Böhnke M, Masters BR. 1999. Confocal microscopy of the cornea. Prog Retin Eye Res, 18:553-628.
Böhnke M, Thaer A, Schipper I. 1998. Confocal microscopy reveals persisting stromal changes after myopic photorefractive keratectomy in zero haze corneas. British Journal of Ophthalmology, $82: 1393-400$

Böhnke M, Masters BR. 1997. Long-term contact lens wear induces a corneal degeneration with microdot deposits in the corneal stroma. Ophthalmology, 104:1887-96.

Bragheeth MA, Dua HS. 2005. Corneal sensation after myopic and hyperopic LASIK: clinical and confocal microscopic study, $\mathrm{Br} J$ Ophthalmol, 89:580-5.

Brookes NH, Loh I-P, et al. 2003. Involvement of corneal nerves in the progression of keratoconus. Experimental Eye Research, 77:515-24.

Brugin E, Ghirlando A, Gambato C, et al. 2007. Central corneal thickness: z-ring corneal confocal microscopy versus ultrasound pachymetry. Cornea, 26:303-7.

Calvillo MP, McLaren JW, Hodge DO, et al. 2004. Corneal reinnervation after LASIK: prospective 3-year longitudinal study. IOVS, 45:3991-6.

Cavanagh HD, McCulley JP. 1996. In vivo confocal microscopy and Acanthamoeba keratitis. Am J Ophthalmol, 121:207-8.

Cavanagh HD, Petroll WM, Alizadeh H, et al. 1993. Clinical and diagnostic use of in vivo confocal microscopy in patients with corneal disease. Ophthalmology, 100:1444-54.

Chang PY, Carrel H, Huang JS, et al. 2006. Decreased density of corneal basal epithelium and subbasal corneal nerve bundle changes in patients with diabetic retinopathy. Am J Ophthalmol, 142:488-90.

Chew SJ, Beuerman RW, Assouline M, et al. 1992. Early diagnosis of infectious keratitis with in vivo real time confocal microscopy. CLAO Journal, 18:197-201.

Chiou AG, Beuerman RW, Kaufman SC, et al. 1999. Confocal microscopy in lattice corneal dystrophy. Graefes Archive for Clinical and Experimental Ophthalmology, 237:697-701.

Chiou AG, Kaufman SC, Beuerman RW, et al. 1999a. Confocal microscopy in cornea guttata and Fuchs' endothelial dystrophy. British Journal of Ophthalmology, 83:185-9.

Chiou AG, Kaufman SC, Beuerman RW, et al. 1999b. Confocal microscopy in posterior polymorphous corneal dystrophy. Ophthalmologica, 213:211-13

Chiou AG, Kaufman SC, Beuerman RW, et al. 1999c. Differential diagnosis of linear corneal images on confocal microscopy. Cornea, 18:63-6.

Cohen RA, Chew SJ, Gebhardt BM, et al. 1995. Confocal microscopy of corneal graft rejection. Cornea, 14:467-72.

Corbett MC, Prydal JI, Verma S, et al. 1996. An in vivo investigation of the structures responsible for corneal haze after photorefractive keratectomy and their effect on visual function. Ophthalmology, 103:1366-80.

Efron N, Perez-Gomez I, Morgan PB. 2002. Confocal microscopic observations of stromal keratocytes during extended contact lens wear. Clinical and Experimental Optometry, 85:156-60.

Efron N, Mutalib HA, Perez-Gomez I, et al. 2002. Confocal microscopic observations of the human cornea following overnight contact lens wear. Clinical and Experimental Optometry, 85:149-55.

Efron N, Perez-Gomez I, Mutalib HA, et al. 2001. Confocal microscopy of the normal human cornea. Cont Lens Anterior Eye, 24:16-24.

Erie JC, Patel SV, McLaren JW, et al. 2006. Corneal keratocyte deficits after photorefractive keratectomy and laser in situ keratomileusis. Am J Ophthalmol, 141:799-809.

Erie JC, McLaren JW, Hodge DO, et al. 2005a. Long-term corneal keratoctye deficits after photorefractive keratectomy and laser in situ keratomileusis. Trans Am Ophthalmol Soc, 103:56-66.

Erie JC, McLaren JW, Hodge DO, et al. 2005b. Recovery of corneal subbbasal nerve density after PRK and LASIK. Am J Ophthalmol, 140:1059-64.

Erie JC, McLaren JW, Hodge DO, et al. 2005c. The effect of age on the corneal subbasal nerve plexus. Cornea, 24:705-9.

Erie JC, Patel SV, McLaren JW, et al. 2003. Keratocyte density in the human cornea after photorefractive keratectomy. Archives of Ophthalmology, 121:770-6. 
Erie JC. 2003. Corneal wound healing after photorefractive keratectomy: a 3-year confocal microscopy study. Trans Am Ophthalmol Soc, 101:287-328.

Erie JC, Patel SV, McLaren JW, et al. 2002a. Effect of myopic laser in situ keratomileusis on epithelial and stromal thickness: a confocal microscopy study. Ophthalmology, 109:1447-52.

Erie JC, Patel SV, McLaren JW, et al. 2002b. Keratocyte density in keratoconus. A confocal microscopy study (a). American Journal of Ophthalmology, 134:689-95.

Erie JC, Patel SV, McLaren JW, et al. 1999. Keratocyte density in vivo after photorefractive keratectomy in humans. Transactions of the American Ophthalmological Society, 97:221-36.

Font RL, Fine BS. 1972. Ocular pathology in Fabry's disease. Histochemical and electron microscope observations. Am J Pathol, 97:671.

Grupcheva CN, Wong T, Riley AF, et al. 2002. Assessing the sub-basal nerve plexus of the living healthy human cornea by in vivo confocal microscopy. Clinical and Experimental Ophthalmology, 30:187-90.

Hahnel C, Somodi S, Weiss DG, et al. 2000. The keratocyte network of human cornea: a three-dimensional study using confocal laser scanning fluorescence microscopy. Cornea, 19:185-93.

Harrison DA, Joos C, Ambrosio Jr R. 2003. Morphology of corneal Basal epithelial cells by in vivo slit-scanning confocal microscopy. Cornea, 22:246-8.

Heinz P, Bodanowitz S, Wiegand W, et al. 1996. In vivo observation of corneal nerve regeneration after photorefractive keratectomy with a confocal videomicroscope. German Journal of Ophthalmology, 5:373-7.

Hill JD, inventor. 1994. Confocal tandem scanning reflected light microscope. US Patent 5,307,203.

Hollingsworth J, Perez-Gomez I, Mutalib HA, et al. 2001. A population study of the normal cornea using an in vivo, slit-scanning confocal microscope. Optometry and Vision Science, 78:706-11.

Hollingsworth JG, Efron N, Tullo AB. 2000. A case study of advanced Fuchs' endothelial dystrophy using the confocal microscope. Contact Lens Ant Eye, 23:165.

Hollingsworth JG, Efron N. 2004. Confocal microscopy of the corneas of long-term rigid contact lens wearers. Cont Lens Anterior Eye, 27:57-64.

Hollingsworth JG, Efron N, Tullo AB. 2005. In vivo corneal confocal microscopy in keratoconus. Ophthalmic Physiol Opt, 25:254-60.

Hossain P, Sachdev A, Malik RA. 2005. Early detection of diabetic peripheral neuropathy with corneal confocal microscopy. Lancet, 366:1340-3.

Hosal BM, Ornek N, Zilelioglu G, et al. 2005. Morphology of corneal nerves and corneal sensation in dry eye: a preliminary study. Eye, 19:1276-9.

Inoue $\mathrm{K}$, Kato S, Inoue Y, et al. 2002. The corneal endothelium and thickness in type II diabetes mellitus. Jpn J Ophthalmol, 46:65-9.

Iqbal I, Kallinikos P, Boulton AJM, et al. 2005. Corneal nerve morphology: a surrogate marker for human diabetic neuropathy improves with improved glycaemic control. Diabetes, 54:871.

Jalbert I, Stapleton F, Papas E, et al. 2003. In vivo confocal microscopy of the human cornea. Br J Ophthalmol, 87:225-36.

Jalbert I, Stapleton F. 1999. Effect of lens wear on corneal stroma: preliminary findings. Australian and New Zealand Journal of Ophthalmology, 27:211-13.

Javaloy J, Vidal MT, Villada JR, et al. 2004. Comparison of four corneal pachymetry techniques in corneal refractive surgery. J Refract Surg, 20:29-34.

Joyce NC. 2003. Proliferative capacity of the corneal endothelium. Progress in Retinal and Eye Research, 22:359-89.

Kallinikos P, Morgan P, Efron N. 2004. On the etiology of keratocyte loss during contact lens wear. Invest Ophthalmol Vis Sci, 45:3011-20.

Kallinikos P, Morgan P, Efron N. 2006. Assessment of stromal keratocytes and tear film inflammatory mediators during extended wear of contact lenses. Cornea, 25:1-10.

Kallinikos P, Berhanu M, O'Donnell C, et al. 2004. Corneal nerve tortuosity in diabetic patients with neuropathy. IOVS, 45:418-22.
Kaufman SC, Laird JA, Cooper R, et al. 1996. Diagnosis of bacterial contact lens related keratitis with the white-light confocal microscope. CLAO Journal, 22:274-7.

Kaufman SC, Beuerman RW, Kaufman HE. 1993. Diagnosis of advanced Fuchs' endothelial dystrophy with the confocal microscope. American Journal of Ophthalmology, 116:652-3.

Kauffmann T, Bodanowitz S, Hesse L, et al. 1996. Corneal reinnervation after photorefractive keratectomy and laser in situ keratomileusis: an in vivo study with a confocal videomicroscope. German Journal of Ophthalmology, 5:508-12.

Kaufman SC, Hamano H, Beuerman RW, et al. 1996. Transient corneal stromal and endothelial changes following soft contact lens wear: a study with confocal microscopy. CLAO Journal, 22:127-32.

Kaufman SC, Musch DC, Belin MW, et al. 2004. Confocal microscopy: a report by the American Academy of Ophthalmology. Ophthalmology, 111:396-406.

Kobayashi A, Yokogawa H, Sugiyama K. 2006. In vivo laser confocal microscopy of Bowman's layer of the cornea. Ophthalmology, 113:2203-8.

Kobayashi A, Sugiyama K. 2007. In vivo laser confocal microscopy findings for Bowman's layer dystrophies (Thiel-Behnke and Reis-Bucklers corneal dystrophies). Ophthalmology, 114:69-75.

Lee JS, Oum BS, Choi HY, et al. 2006. Differences in corneal thickness and corneal endothelium related to duration in diabetes. Eye, 20:315-18.

Lee BH, McLaren JW, Erie JC, et al. 2002. Reinnervation in the cornea after LASIK. IOVS, 43:3660-4.

Linna TU, Vesaluoma MH, Pe'rez-Santonja JJ, et al. 2000. Effect of myopic LASIK on corneal sensitivity and morphology of subbasal nerves. IOVS, 41:393-7.

Linna T, Tervo T. 1997. Real-time confocal microscopic observations on human corneal nerves and wound healing after excimer laser photorefractive keratectomy. Current Eye Research, 16:640-9.

Malik RA, Kallinikos P, Abbott CA, et al. 2003. Corneal confocal microscopy: a non-invasive surrogate of nerve fibre damage and repair in diabetic patients. Diabetologia, 46:683-8.

Mantyjarvi M, Tuppurainen K, Ikaheimo K. 1998. Ocular side effects of amiodarone. Surv Ophthalmol, 42:360-6.

Masters BR, Thaer AA. 1995. In vivo real-time confocal microscopy of wing cells in the human cornea: A new benchmark for in vivo corneal microscopy. Bioimages, 3:7-11.

Masters BR, Thaer A. 1994. Real-time scanning slit confocal microscopy of the in vivo human cornea. Applied Optics, 33:695-701.

Mastropasqua L, Nubile M. 2002. Basic principles of confocal microscopy of the cornea. Slack Incorporated, USA, pp. 1-5.

Mathers WD, Sutphin JE, Folberg R, et al. 1996. Outbreak of keratitis presumed to be caused by Acanthamoeba. American Journal of Ophthalmology, 121:129-42.

Mathers WD, Goldberg MA, et al.1997. Coexistent Acanthamoeba keratitis and herpetic keratitis. Arch Ophthalmol, 115:714-18.

McLaren JW, Nau CB, Erie JC, et al. 2004. Corneal thickness measurement by confocal microscopy, ultrasound, and scanning slit methods. Am J Ophthalmol, 137:1011-20.

Mehra S, Tavakoli M, Kallinikos PA, et al. 2007. Corneal confocal microscopy detects early nerve regeneration after pancreas transplantation in patients with type 1 diabetes. Diabetes Care, 10:2608-12.

Minsky M. 1988. Memoir on inventing the confocal scanning microscope. Scanning, 10:128-38.

Mitooka K, Ramirez M, Maguire LJ, et al. 2002. Keratocyte density of central human cornea after laser in situ keratomileusis. American Journal of Ophthalmology, 133:307-14.

Mocan MC, Durukan I, Irkec M, et al. 2006. Morphologic alterations of both the stromal and subbasal nerves in the corneas of patients with diabetes. Cornea, 25:769-73.

Moilanen JA, Vesaluoma MH, Muller LJ, et al. 2003. Long-term corneal morphology after PRK by in vivo confocal microscopy. Investigative Ophthalmology and Visual Science, 44:1064-9. 
Morishige N, Chikama TI, Sassa Y, et al. 2001. Abnormal light scattering detected by confocal biomicroscopy at the corneal epithelial basement membrane of subjects with type II diabetes. Diabetologia, 44:340-5.

Müller LJ, Pels L, Vrensen GFJM. 1996. Ultrastructural organisation of human corneal nerves. IOVS, 476-88.

Müller LJ, Vrensen GFJM, Pels L, et al. 1997. Architecture of human corneal nerves. IOVS, 38:985-94.

Mustonen RK, McDonald MB, Srivannaboon S, et al. 1998. Normal human corneal cell populations evaluated by in vivo scanning slit confocal microscopy. Cornea, 17:485-92.

Mustonen RK, McDonald MB, Srivannaboon S, et al. 1998. In vivo confocal microscopy of Fuchs' endothelial dystrophy. Cornea, 17:493-503.

O’Donnell C, Efron N. 2004. Corneal endothelial cell morphometry and corneal thickness in diabetic contact lens wearers. Optom Vis Sci, 81:858-62.

O'Donnell C, Efron N, Boulton AJ. 2001. A prospective study of contact lens wears in diabetes mellitus. Ophthalmic Physiol Opt, 21:127-38.

Oliveira-Soto L, Efron N. 2001. Morphology of corneal nerves using confocal microscopy. Cornea, 20:374-84.

Oliveira-Soto L, Efron N. 2003. Morphology of corneal nerves in soft contact lens wear. A comparative study using confocal microscopy. Ophthalmic and Physiological Optics, 23:163-74.

Oliveira-Soto L, Efron N. 2003. Assessing the cornea by in vivo confocal microscopy. Clinical and Experimental Ophthalmology, 31:83-4.

Patel S, Reinstein DZ, Silverman RH, et al. 1998. The shape of Bowman's layer in the human cornea. $J$ Refract Surg, 14:636-40.

Patel SV, McLaren JW, Hodge DO, et al. 2002. Confocal microscopy in vivo in corneas of long-term contact lens wearers. Investigative Ophthalmology and Visual Science, 43:995-1003.

Patel DV, McGhee CN. 2006. Mapping the corneal sub-basal nerve plexus in keratoconus by in vivo laser scanning confocal microscopy. IOVS, 47:1348-51.

Patel DV, McGhee CN. 2005. Mapping of the normal human corneal subbasal nerve plexus by in vivo laser scanning confocal microscopy. IOVS, 46:4485-8.

Petroll WM, Jester JV, Cavanagh HD. 1996. In vivo confocal imaging. Int Rev Exp Pathol, 36:93-129.

Pe'er J, Vidaurri J, Halfon ST, et al. 1983. Association between corneal arcus and some of the risk factors for coronary artery disease. $\mathrm{Br} J$ Ophthalmol, 67:795-8.

Perez-Gomez I, Efron N. 2003. Change to corneal morphology after refractive surgery (myopic laser in situ keratomileusis) as viewed with a confocal microscope. Optometry and Vision Science, 80:690-7.

Pfister DR, Cameron JD, Krachmer JH, et al. 1996. Confocal microscopy findings of Acanthamoeba keratitis. Am J Ophthalmol, 121:119-28.

Pisella PJ, Auzerie O, Bokobza Y, et al. 2001. Evaluation of corneal stromal changes in vivo after laser in situ keratomileusis with confocal microscopy. Ophthalmology, 108:1744-50.

Quadrado MJ, Popper M, Morgado AM, et al. 2006. Diabetes and corneal cell densities in humans by in vivo confocal microscopy. Cornea, 25:761-8.

Richter A, Slowik C, Somodi S, et al. 1996. Corneal reinnervation following penetrating keratoplasty: correlation of esthesiometry and confocal microscopy. Ger J Ophthalmol, 5:513-17.

Rosenberg ME, Tervo TM, Muller LJ, et al. 2002. In vivo confocal microscopy after herpes keratitis. Cornea, 21:265-9.

Rosenberg ME, Tervo TM, Immonen IJ, et al. 2000. Corneal structure and sensitivity in type 1 diabetes mellitus. Invest Ophthalmol Vis Sci, $41: 2915-21$
Roszkowska AM, Tringali CG, Colosi P, et al. 1999. Corneal endothelium evaluation in type I and type II diabetes mellitus. Ophthalmologica, 213:258-61.

Simo Mannion L, Tromans C, O'Donnell C. 2005. An evaluation of corneal nerve morphology and function in moderate keratoconus. Cont Lens Anterior Eye, 28:185-92.

Somodi S, Hahnel C, Slowik C, et al. 1996. Confocal in vivo microscopy and confocal laser-scanning fluorescence microscopy in keratoconus. Ger J Ophthalmol, 5:518-25.

Stachs O, Zhivov A, Kraak R, et al. 2006. In vivo three-dimensional confocal laser scanning microscopy of the epithelial nerve structure in the human cornea. Graefes Arch Clin Exp Ophthalmol, DOI 10.1007/ s00417-006-0387-2.

Sutphin JE, Kantor AL, Mathers WD, et al. 1997. Evaluation of infectious crystalline keratitis with confocal microscopy in a case series. Cornea, 16:21-6.

Su Pei-Yuang, Fung-Rong Hu, Yen-Ming Chen, et al. 2006. Dendritiform cells found in central cornea by in-vivo confocal microscopy in a patient with mixed bacterial keratitis. Ocul Immunol Inflamm, 14:241-4.

Tavakoli M, Mehra S, AugustineT, et al. 2006. Early neural regeneration after pancreas transplantation detected by corneal confocal microscopy: A pilot Study. Diabetic Medicine, 23(Suppl 2):P98.

Tervo T, Moilanen J. 2003. In vivo confocal microscopy for evaluation of wound healing following corneal refractive surgery. Progress in Retinal and Eye Research, 22:339-58.

Tervo TM, Moilanen J, Rosenberg ME, et al. 2002. In vivo confocal microscopy for studying corneal diseases and conditions associated with corneal nerve damage. Adv Exp Med Biol, 506:657-65.

Tomii S, Kinoshita S. 1994. Observations of human corneal epithelium by tandem scanning confocal microscope. Scanning, 16:305-6.

Tuominen IS, Konttinen YT, Vesaluoma MH, et al. 2003.Corneal innervation and morphology in primary Sjogren's syndrome. IOVS, 44:2545-9.

Waring GO, Bourne WM, et al.1982. The corneal endothelium. Normal and pathologic structure and function. Ophthalmology, 89:531-90.

Werner LP, Werner L, Dighiero P, et al. 1999. Confocal microscopy in Bowman and stromal corneal dystrophies. Ophthalmology, 106:1697-704.

Wiebers DO, Hollenhorst RW, Goldstein NP. 1977. The ophthalmologic manifestations of Wilson's disease. Mayo Clin Proc, 52:409-16.

Wilson T, Sheppard CJR. 1984. Theory and practice of scanning optical microscopy. London: Academic Press.

Wilson SE, Hong JW. 2000. Bowman's layer structure and function: critical or dispensable to corneal function? A hypothesis. Cornea, 19:417-20.

Winchester K, Mathers WD, Sutphin JE, et al. 1995. Diagnosis of Acanthamoeba keratitis in vivo with confocal microscopy. Cornea, 14:10-17.

Winchester K, Mathers WD, Sutphin JE. 1997. Diagnosis of Aspergillus keratitis in vivo with confocal microscopy. Cornea, 16:27-31.

Zhivov A, Vollmar B, Guthoff R. 2005. In vivo confocal microscopic evaluation of Langerhans cell density and distribution in the normal human corneal epithelium. Graefes Arch Clin Exp Ophthalmol, 243:1056-61.

Zhivov A, Stave J, Vollmar B, et al. 2007. In vivo confocal microscopic evaluation of langerhans cell density and distribution in the corneal epithelium of healthy volunteers and contact lens wearers. Cornea, $26: 47-54$ 
